PENELOPE HARALAMBIDOU

\title{
C for CAMERA OBSCURA (REVERSED)
}

\section{In Front of the Looking Door}

Defying traditional definitions of painting or sculpture Duchamp's final work is an enigmatic assemblage of elements, a carefully constructed diorama, with an equally enigmatic title: Étant donnés: $1^{\circ}$ la chute d'eau, $2^{\circ}$ le gaz d'éclairage ... (Given: 1 . The Waterfall, 2. The Illuminating Gas ...), or Given.

The title derives from a note by Duchamp that refers directly to his earlier major piece the Large Glass:

Preface

Given 1st the waterfall

2nd the illuminating gas

Determine the setting for an instant Pause (or allegorical appearance), of a succession of a set of phenomena seeming to necessitate each other according to laws, in order to isolate, the sign of accordance between this Pause (open to all countless eccentricities), on one hand, and a choice of possibilities legitimised by these laws (and also causing them), on the other. ${ }^{1}$

After convincing the world that he had abandoned art for chess, Duchamp worked on Given in complete secrecy for twenty years. Just before his death in 1968, he arranged for it to be permanently installed at the Philadelphia Museum of Art, but when this was unveiled to the public a year later, unlike his accompanying detailed notes for the Large Glass, there were no clues to its significance and meaning. ${ }^{2}$

Standing in front of an old weathered door in a darkened, empty room, the viewer engages through two peepholes with a concealed pornographic scene, bathed in bright light: a recumbent, faceless, female nude, holding a gas lamp and submerged in twigs in the open landscape. The scene is strangely tranquil and silent, as if paused, while at the background a waterfall silently glitters.

By using part of a note referring to the Large Glass as a title for Given, Duchamp may have implied that this is his second attempt to determine the setting for an "instant Pause" or "allegorical appearance" of the Bride. If Given is the setting for an allegory - in 
the sense suggested by the Greek etymology of the word allos, other, and agoria, speaking - it is a pornographic image that says one thing and means another. Furthermore, the title reads as a mathematical problem an algebraic equation: given $a$ and $b$, define $c$-perhaps a task that he set to himself. Whether an allegory, a mathematical problem or a scene under forensic examination, Given also confronts the viewer with an enigma. The lack of any direct explanation by the artist, in combination to the cryptic title, may suggest that Duchamp is intentionally asking the viewer to offer a solution to his allegorical equation: Given the waterfall and the illuminating gas, define the hidden meaning behind the allegorical setting of Given.

The ideas and work presented here is my response to Duchamp's call for the interpretation of Given, which takes the form of a forensic investigation based on analysis of the evidence found in Duchamp's work and using my probing 'redrawing' of it as a method. Most of this research can be found in Marcel Duchamp and the Architecture of Desire a book that also traces the links between his work and architectural thinking. ${ }^{3}$

I will not focus on the brightly lit assemblage, however, but on the door that separates it from the viewer and the space immediately in front of it - not on what lies behind the door, but in front of the door: the space outside Given. ${ }^{4}$ Most of the analysis that ensues goes back some 17 years, but some new thoughts were triggered, through recent conversations with the artist Serkan Ozkaya.

My first encounter with the assemblage in person was in 2000, when I visited the Philadelphia Museum of Art for the first time. The piece is found - sometimes it feels as if by chance - in darkened room off the main gallery. Entering this dimly lit room, on the left, at the back, a brick porch frames a weathered wooden door, which marks the first encounter with Given. ${ }^{5}$ The hinged rotation and spatial ambiguity that a door denotes always fascinated Duchamp. Throughout his career, a series of artworks take the form of a door, or a window and play with reversals: interior/exterior, transparency/opacity, back/front, looking through/passing through. ${ }^{6}$ The door in the Philadelphia Museum has a similar ambiguous spatiality. Is the door an obstacle obscuring the view beyond, or an interface through which the view is constructed?

More often than not, works of art in a museum demand the visitors' contemplation from a distance: "Please do not touch". In Given, the door - an everyday architectural element that reduces the contemplative distance between viewer and exhibit - invites the visitor 
to come closer. A door suggests the existence of a space beyond, but is also a barrier, hiding the view and controlling the passage to that space. If it were to be pushed open, what would lie behind it? On closer inspection its weathered appearance and lack of handle eliminate the possibility of physically crossing this boundary. However, light emanating from the peepholes suggests that something lies beyond. A view to an, up to that point hidden luminous, space is projected further in. Before reaching this weathered boundary, the viewer, or voyeur according to Duchamp, is as if blind, oblivious of the subsequent expansion of the visual field: to see through the door, the voyeur needs to come close and touch. However, what they will perceive beyond the door is an illusory, constructed - purely for optical purposes - space, which is clearly beyond touch. The boundary of the door thus reveals itself as both a tactile terminal and a visual portal projecting the gaze into the high visuality of the scene.

Photographs of the door, showing a worn and unwelcoming surface, fail to convey the tactile nuances of the physical experience of approaching it and looking through it. When encountered in real life in the gallery, a series of details in the general arrangement of the door subtly welcome the viewer and take account of his or her body. First, the two lower panels are at a slight angle to each other, creating a shallow alcove for one's feet. This allows a closer contact of the upper body with the top part of the door. Duchamp has clearly designed this overlooked detail, as is obvious in his Manual of Instructions. In a note referring to a composite photograph of the door on page 16, written on the back of a flap attached on page 15, he suggests:

The 2 lower panels on the left and the 2 lower panels on the right meet at a slight concave angle (seen from in front of the door). ${ }^{7}$

On the same page he has also marked the angle directly on the photograph with blue biro and written: angle concave.

Another feature, difficult to decipher in most photographs and only perceptible at a very close proximity to the door, is a hidden gap at the joint between the two upper panels immediately below the two peepholes. This gap creates a narrow nook for the nose, so that the door fits like a mask. ${ }^{8}$ Unlike Duchamp's clear instruction about the lower panels, there is no mention of this detail in the manual of instructions, so it is not certain whether the gap was there originally, or whether it is the result of a breakage after repeated viewing. 
This arrangement facilitates a close encounter of the viewer's body with the door, allowing the face to press into its wooden surface and the eyes to rest deep into the peepholes. This repetitive pressing of viewers' faces on the surface has created a distinctive smell of human skin oil, mixed with that of wood - reminiscent of the smell of wooden icons in Orthodox churches, continually pecked by worshippers for centuries. But apart from an olfactory presence, this indiscernible, incessant deposit has also left a visible mark on the door. The act of looking through the peepholes constructs an apparition of a face, a darker outline with bleached out circles around the "eyes": a collective portrait of voyeurism, looking back at the viewer as he or she approaches the door.

This series of nuanced details in the experience of the door create a subtle sense of occupancy, an "infra-thin" region immediately in front of the door. Infra-thin (inframince) is a term invented by Duchamp and used to describe spatial experiences and material transformations at the limits of perception. Duchamp has explored the term in a series of notes hand-written in French accompanied by sketch diagrams, which also ponder the passage from two to three dimensions. ${ }^{9}$ The low-relief modelling of the door's front surface is a concave mould in the shape of the human body that embodies the passage from the flat boundary of the door to the unforeseen expansion into three dimensions immediately behind it. This 'anthropomorphic' door with two peepholes brings to the surface the binocular corporeality of vision. American art theorist Rosalind Krauss notes:

To be discovered at the keyhole is, thus, to be discovered as a body; it is to thicken the situation given to consciousness to include the hither space of the door, and to make the viewing body an object for consciousness. ${ }^{10}$

During the time of my first visit to the Philadelphia museum of Art in 2000, I was very interested in the connection between Given and the stereoscope. The visual sensation of depth and three dimensions registers from a single position and not by any additive spatial movement and exploration around the scene, which the door denies. Therefore, the door stages and accentuates binocular depth in a way similar to a stereoscope, where the illusory representation of normal visual space is also paused. American art historian and critic Craig Adcock has commented on the door's similarities to the stereoscope and also links this to Duchamp's fascination with the fourth dimension: 
Duchamp's tableau represents only a portion of what could be necessary for a threedimensional stereoscopic image of a four-dimensional "Bride." Most critical, there is no place for viewers to station their points of view. With their eyes fixed at the peepholes, they do not have an extra-dimensional point of view as would be required for a genuine four-dimensional perception. From their position in three-dimensional space, they are in a situation analogous to seeing a stereopticon slide from inside the slide. ${ }^{11}$

I suggest that stereoscopy may have influenced not only the arrangement, but also the recording and construction of the central element, the 'visual cast' of the nude, through the use of a stereo-photogrammetry and analogue stereo-plotting, a technique used for mapping. ${ }^{12}$ Inspired by the principles of the analogue stereo-plotter in 2001, I designed Exposure a drawing/installation/projection that stages a virtual simulacrum of Given through the technique of the anaglyph. The anaglyph involves encoding of the images of the stereoscopic pair in chromatically opposite colours - typically red and cyan. ${ }^{13}$ The two, usually printed, images are superimposed and the stereoscopic effect is achieved by using gelatine red and green, or blue, glasses.

To create my anaglyph I used the stereoscopic pair of photographs of Given I took from each peephole during my first visit to the museum. I digitally manipulated the two photographs to accentuate the outlines and assigned monochrome tints of red for the left and cyan for the right eye. I then transferred each image onto colour positive film and created two $35 \mathrm{~mm}$ slides. Using two slide-projectors placed next to each other, I projected the images onto a plain white wall, so as to render a full-scale view of the interior. ${ }^{14}$ The two projectors were arranged in such a way so that the two slightly disparate images match on the figure of the waterfall, because this is one of the furthest most points in the assemblage. Apart from the partial clarity of the waterfall on the wall, the two superimposed images created an initially indecipherable pattern of red and cyan lines. As in normal anaglyphic representations the full depth of the scene was visible by wearing red and green glasses.

Additionally, by entering the space of the image and holding upright a sheet of paper like an individual small screen, I could perform haptically what the eyes do automatically: merge the corresponding points of the two separate views to cast three-dimensional depth. By moving the paper backwards and forwards, and walking in this ethereal architecture of light I could determine the exact point of convergence between red and cyan local shapes, and thus occupy physically the virtual space of the interior. The gas 
lamp, the tips of the branches, the background, the edge of the breach in the wall, and parts of the nude's skin could all be 'touched' in this way. As if passing through the door, and walking inside the luminous three-dimensional drawing of Given, I was able to visually "touch" the whole illusory space of the assemblage including the nude. Although physically absent, and visually coded in a complex overlapping of red and green lines, the interior architecture of Given was virtually there, exposed.

However, during the same first visit at the museum, I failed to recognize another significant attribute of the door. This appeared to me as if in a flash of intuition, unexpectedly, a year later back at home in London. I was sitting at my desk drawing out an imaginary image from the point of view of the nude, the image that would form if she were to turn her head and look towards the door and through the broken wall. Gliding on the imaginary line of her gaze through the peepholes I suddenly realised that not only her gaze, but also all light within the assemblage travels through the peepholes and out beyond the door, forming a "camera obscura". My linking of Given with the device was inspired by British architect and urban and built form theorist Professor Philip Steadman and his work on the role of the camera obscura in Vermeers' painting practice. ${ }^{15}$ According to Steadman's description of the camera obscura:

If a small hole is made in the wall of a darkened room, an image of the scene outside can be formed by light rays passing through the hole. The image may appear on a wall opposite the hole, or can be observed on a sheet of paper or other screen placed in front of the hole. The hole can be in a door, say, or in a solid wooden window shutter. ${ }^{16}$

Although I was not aware of it at the time, I found out later that French art critic Jean Clair has also noted a similarity with the camera obscura. He suggests that in Given the function of the camera obscura is reversed:

In Étant donnés everything takes place as if the device were working in reverse: the beholder is thrust back to the other side of the two circumscribed spaces outside the brick wall and outside the door, as if into a darkness of an outer world. Conversely, the real, bright, visible world, with the trees, the water and the woman, is entirely contained inside the box. While the classical camera obscura was an instrument which articulated the three-dimensional and the two-dimensional, by the intermediary of a monocular opening, it appears - this is a pure hypothesis - as if Étant donnés might be an instrument capable of projecting a three-dimensional 
image, a perfect simulacrum of our world, through a dark room and a twin peephole, outside in a mysterious expanse. ${ }^{17}$

By projecting out the light the door forms a double camera obscura "picturing" the internal scene and forming two inverted and mirrored pools of light, two images of the view behind the door. It makes images of the interior independently of a camera. Adding to its anthropomorphic attributes the door can therefore "see" through the peepholes and projects its vision into the space of the dark vestibule in front of the door.

Convinced of my conjecture about the image making abilities of the door, I was only able to actually test it on my next visit to the museum nine years later. In Given, the intense light of the interior projects through the peepholes and the crack between the two panels. By placing on the plane of the door a sheet of translucent paper, three clear-cut brightly lit shapes become visible: two eyes and long nose. If the paper is removed from the plane of the door, however, and held at a distance of approximately $20 \mathrm{~cm}$, the white light patterns corresponding to the two peepholes start shifting into the double upside down and mirrored idols of the nude in the landscape. A blurry trace of the outlines of the main shapes, pink for the flesh and blue for the sky, reveals the door's ability to draw the double image of Given in light. So Given is indeed a double camera obscura in reverse: not a dark chamber into which images of the outside world are projected, but a hidden, intensely lit and three-dimensional diorama that projects a pair of images outwards.

While approaching the door and just before visual contact with the scene, the peepholes cast these luminous images on the face of the voyeur. Upside down and reversed, a simulacrum of the nude marks each eyelid, a pool of bright blue colours each cheek and the nude's gas lamp registers a line under each eye. ${ }^{18}$ Unassisted, the two images are blurred, but placing two simple magnifying lenses in front of both holes focuses the views in sharp detail. Duchamp's door is incessantly "looking” independently of an observer, his vision machine constantly drawing out the deep space of the interior. If these two detailed images of light were captured on a photosensitive surface they would form a stereoscopic pair from which the geometry of the assemblage could be measured. Consequently, the arrangement of Given not only provides a hidden spectacle, but is a drawing machine, drawing in light the pair of images from which it can be recreated in three dimensions. More significantly, Duchamp's door exposes the role of photography - from the Greek $\varphi \omega \varsigma$ (phos) "light" and $\gamma \rho \alpha \varphi \eta$ (graphé) "drawing" - in the construction of imagination and vision, while at the same time confounding the 
old discord between emission and intromission theories.

Duchamp famously stated that the creative act is not performed by the artist alone, and stressed the role of the spectator in completing the work of art. He obviously meant this as an intellectual completion, an appreciation, recognition and understanding of the work of art that also valorises it. In Given, however, the spectator's completion of the work acquires a visceral dimension. The door uses the body of the spectator as the receptacle within which the three-dimensional relief of view behind it is cast. The spectator/viewer/voyeur provides the lenses - eyes - and the photosensitive substrate - retinas- as well as the complex architecture of the optic nerves crossing at the optic chiasma to imprint a deep image of Duchamp's constructed daydream into his or her mind.

But what happens when he or she does not block the peepholes with his or her body? When Clair talks about the projection he refers to an "outer world" or a "mysterious expanse" discounting the existing vestibule, the darkened room immediately outside Given. This room with a flat empty white wall opposite the door becomes an ideal screening room for the piece's projecting powers. If the room were appropriately darkened the double projection of the interior would become visible on the opposite wall. ${ }^{19}$

Beyond the formation of the image on the wall however, the dimly lit vestibule in front of Given is occupied by the imperceptible interweaving of the two projections, which redraw the naked body in light. Clair also hypothesises that Given "might be an instrument capable of projecting a three-dimensional image, a perfect simulacrum of our world". If there was a way of marking the points on which the two cones of light intersect, would a simulacrum of the scene appear reversed and upside down in the middle of the room? Does the door in Given cast a second four-dimensional allegorical appearance of the nude? Perhaps the hidden significance of Given lies not behind the door, but in front of it.

\footnotetext{
${ }^{1}$ Marcel Duchamp, Duchamp du signe, ed. Michel Sanouillet and Elmer Peterson (Paris: Flammarion, 1994), 43-44. My translation of the French.

2 Duchamp left a matter-of-fact manual of instructions for putting the piece together, which includes a series
} 
of numbered 'operations' and annotated sketches and photographs. See, Marcel Duchamp, Manual of Instructions for Étant donnés: $1^{\circ}$ la chute d'eau, $2^{\circ}$ le gaz d'éclairage (Philadelphia: Philadelphia Museum of Art, 1987). For an in depth analysis of Given see Michael Taylor, Marcel Duchamp: Étant donnés (Philadelphia: Philadelphia Museum of Art; and New Haven and London: Yale University, 2009). 3 Penelope Haralambidou, Marcel Duchamp and the Architecture of Desire (London: Routledge, 2013). ${ }^{4}$ For a work that analyses the act of looking through the peepholes and the view behind the door, see Chapter 4, "Visuality: The Act of Looking" in Haralambidou, Marcel Duchamp, 181-227.

5 Visitors at the Philadelphia Museum of Art not looking out for Given specifically might miss it altogether.

${ }^{6}$ For example, in 1927 he installed in his studio Door: 11 rue Larrey, a single door that closed off either the bathroom or the bedroom, so that it was always both open and closed.

${ }^{7}$ See insert with translation of notes and annotations in the second edition of Duchamp's, Manual of Instructions: Marcel Duchamp, Manual of Instructions for Étant donnés: $1^{\circ}$ la chute d'eau, $2^{\circ}$ le gaz d'éclairage (Philadelphia: Philadelphia Museum of Art; and New Haven and London: Yale University, 2009), xi. 8 The oval holes are conical, opening up towards the scene. Behind the panel of the door and the holes is a velvet curtain, which can be touched through a third hole on the right hand side panel. Nothing can be seen through that opening, but as the mark around it reveals, that does not stop viewers trying, as looking through that point of view would most likely reveal the nude's face.

${ }^{9}$ See Marcel Duchamp, Notes (Paris: Flammarion 1999), and Jean Clair, Duchamp et la photographie: Essai d'analyse d'un primat technique sur le développement d'une oeuvre (Paris: Chêne, 1977), 94.

10 Rosalind Krauss, The Optical Unconscious (Cambridge: MIT, 1994), 112.

${ }^{11}$ Craig Adcock, “Duchamp's Way: Twisting Our Memory of the Past 'For the Fun of It'”, in The Definitively Unfinished Marcel Duchamp, ed. Thierry de Duve (Cambridge: MIT, 1991), 330.

12 For more details, see Chapter 3, "The Blossoming of Perspective: An Architectural Analysis of Given" in Haralambidou, Marcel Duchamp, 55-179, and Penelope Haralambidou, “The Stereoscopic Veil,"

Architectural Research Quarterly, 11.1 (March 2007): 36-51.

13 Duchamp was fascinated by anaglyphs and at least two of his works employ the technique directly: Anaglyphic Film, 1920 and Cheminée Anaglyphe, 1968.

14 I was able to calculate the dimensions of the breach from the information in Duchamp's Manual of Instructions.

15 Steadman's mathematical and geometrical analysis of the role of the optical machine in the Dutch artist's work has influenced my study of Duchamp's Given both in terms of subject matter and methodology. See, Philip Steadman, Vermeer's Camera: Uncovering the Truth Behind the Masterpieces (Oxford: OUP, 2001). 16 Steadman, Vermeer's Camera, 14.

17 Jean Clair, "Duchamp and the Classical Perspectivists," Artforum 16, (March 1978): 48.

18 My recent discussions with Serkan Ozkaya led to the creation of a new work to specifically accompany my essay for PUBLIC, see figure X.

${ }^{19}$ Serkan Ozkaya is currently constructing a reproduction of Given with the specific aim of testing the picture making properties of the door and revealing the double image created by the two peepholes. 